\title{
The electromagnetic radiations and its impacts on bird diversity in India
}

\begin{abstract}
Cellular phones are essential to our lives and so are the cellular phone base stations. They are not simply free standing towers but a balloon of invisible electromagnetic field with radiations that continue to threaten life around them, specifically of the birds. This article explores the various published scientific studies of the effects that electromagnetic radiations produce on various bird species in India. Relevant information was collected from different peer reviewed publications on how the electromagnetic radiations have been impacting the bird species. Research results from the available studies are presented and discussed. The limited number of observations and studies endorse the negative impacts the electromagnetic radiations carry for the various bird species in the country. Overall, there is a decline in the diversity of the bird species. Therefore, it becomes important to pay considerable attention to the observed patterns and opt for a sustainable development approach for the protection of bird species.
\end{abstract}

Volume 5 Issue I - 2020

\section{Kirandeep K Dhami}

Department of Botanical \& Environmental Sciences, Guru Nanak Dev University, India

\begin{abstract}
Correspondence: Kirandeep K Dhami,Assistant Professor, Guru Nanak Dev University, Amritsar, Punjab, India, Email kirandeepdhami@gmail.com
\end{abstract}

Received: February 25, 2020 | Published: July 03, 2020

\section{Introduction}

Electromagnetic field and radiations that are invisible to human eye are omnipresent. There are several natural and anthropogenic sources that generate electromagnetic field in the surrounding air like television towers, radio towers and cell phone towers. Amongst the various anthropogenic sources, cellular mobile base stations are the major contributors to the electromagnetic field and radiations in the immediate environment. Since the introduction of wireless technology, the spread of electromagnetic field has increased massively in the surrounding air. Before the cell phones came into existence, electromagnetic radiation emission was sporadic from a few radio or television transmitters only. The invent and spread of cell phones to almost every individual in every home around the world has massively increased the amount of unseen electromagnetic radiations into the atmosphere. ${ }^{1}$
It must be noted here that the radio/television transmitters transmit a weak radiofrequency (above $10 \mathrm{MHz}$ ) field while all the electrical appliances transmit a low frequency (upto $300 \mathrm{~Hz}$ ) electromagnetic field or intermediate frequency $(300 \mathrm{~Hz}-10 \mathrm{MHz})$ electromagnetic field (Figure 1).On the other hand, cellular phones and the mobile base stations transmit a strong electromagnetic field. Cell tower antennas with CDMA technology transmit electromagnetic field and radiations in the frequency range of $869-894 \mathrm{MHz}$, whereas the cell phone tower antennas with GSM 900 and GSM 1800 technology, transmit electromagnetic field with a frequency range of 935-960 $\mathrm{MHz}$ and $1810-1880 \mathrm{MHz}$. respectively. ${ }^{2}$ It is noteworthy here that the strength of electromagnetic field and radiations is maximum close to the towers, which decreases with the increase in distance from these towers. $^{3}$

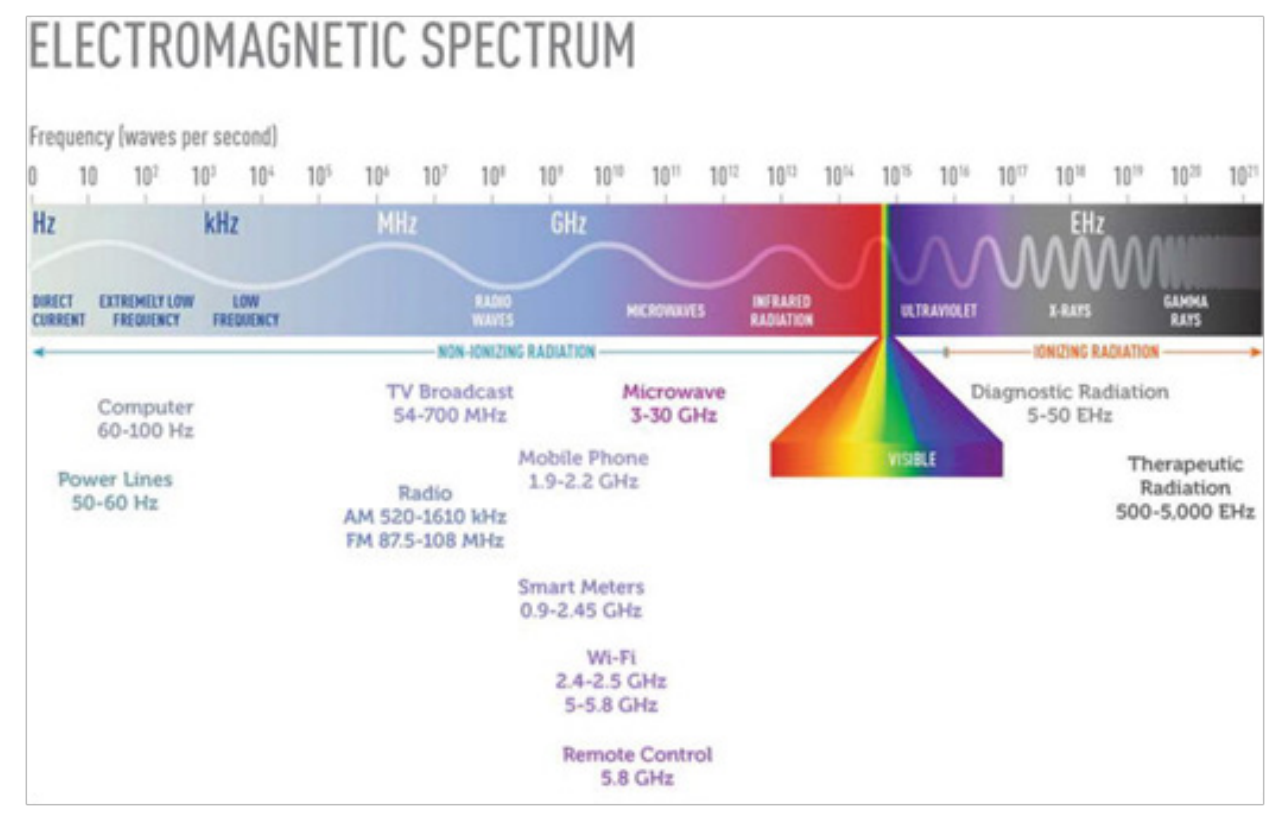

Figure I A range of frequencies (the spectrum) of electromagnetic radiation and their respective wavelengths. 
Radiation from cellular mobile base stations is almost identical to that from mobile phones of the same system (GSM 900 or 1800), except that it is simply more powerful. GSM 900 mobile phones emit radiations with a frequency between 890 and $915 \mathrm{MHz}$, while base stations emit radiations between 935 and $960 \mathrm{MHz} .{ }^{4}$ Overall, stronger the field, greater is the undesirable impact of the electromagnetic field on life. ${ }^{3,5}$ With mobile phones becoming necessary tool in the lives of 7 billion people on the earth, it poses a serious threat to all variety of life forms from the exposure to manmade electromagnetic field and radiations.

The main objective of this review is to study a pattern of impacts the electromagnetic radiations have on various bird species in India. This article mainly compiles the published work that studies the impacts of anthropogenic electromagnetic field and radiations on the avian life in one of the most populated country of India.

\section{Birds and cellular mobile base stations}

Several countries have observed a reduction in bird diversity coinciding with the proliferation of Cellular Mobile Base stations (GSM 900 or 1800). ${ }^{1,6}$ The most prominent example of this impact comes from the UK where a huge decline in several species of urban birds was observed, including the sparrows. The sparrow population in the country declined from 24 million to 14 million birds in the period of 30 years. ${ }^{2}$ An abrupt decline with $75 \%$ descent occurred between 1994 and 2002 that coincided with the rollout of mobile technology in the country.

Similar scenario has been observed in Valladolid, Spain, where a reduction in species diversity in birds and breeding couples occurred since several cellular phone base stations got installed between 1997 to $2007 . .^{1}$ Out of a total 14 bird species found in the city, three species completely disappeared during this time period, while four showed a decline in their populations with seven others in stable state. Overall, the bird population in the city decreased. Similarly, the productivity of White stork (Ciconiaciconia) in nests located far away to cellular phone Base stations was observed to be higher than in the nests located within $200 \mathrm{~m}$ of antennaein Spain. ${ }^{7}$ In Belgium, many sparrows disappeared recently. ${ }^{5}$ There was found a strong correlation between spatial variation in number of house sparrows with the strength of electromagnetic field. Indian scenario is no different than the observed in various parts of the world.

\section{Biodiversity in India}

India is very well known for its biodiversity. It is one of the seventeen mega diverse countries in the world with only $2.4 \%$ of the world's land area that accommodates about 7-8 \% of overall species found around the world. ${ }^{8}$ The biological richness of the country is evident from the fact that it accounts 45,000 species of plants and 91,000 species of animals that represent almost $7 \%$ and $6.5 \%$ of world's flora and fauna respectively. Out of a total of 10,000 species of birds found all over the world, almost 1230 species are found in India only. Overall, almost $13 \%$ of the world's bird species found in India are under threat for various reasons: climate change, pollution and strong electromagnetic fields.

Like in different parts of the world, Indian cities have observed a decline in the overall abundance in birds in various parts of the country. ${ }^{2,9,10}$ Bird population and density declined closer to the cellular phone base stations. This could be attributed to reduced reproductive success in the birds. In the state of Punjab, birds of different species were observed to have lowered breeding success close to cell phone base stations. Similar observations were made in the town ofBijapurin the state of Uttar Pradesh. A reduction in bird population was recorded in ten species of the birds commonly found in the city. ${ }^{10}$ Scenario was no different in the central parts of the country. In the town Drug in the state of Madhya Pradesh, population density in 13 species of birds declined where 27 cell phone base stations were installed. ${ }^{11}$ In Southern Parts of the country in Chennai, four of the 200-odd Chennai birds; house sparrow (Passer domesticus), red whiskered bulbul (Pycnonotusjocosus), brahmini kite (Haliasturindus) and spotted dove (Streptopeliachinensis) have virtually disappeared. These are birds which have always been around. Now they are nowhere to be seen. Disappearance of house sparrows has been reported from different parts of the country. Birds are known to be sensitive to magnetic radiation. Increasing number of cell phone towers in cities apparently are bringing down bird population. The microwaves (300 $\mathrm{MHz}$ to $300 \mathrm{GHz}$ ) emitted by cell phone towers and handsets has been found to be responsible for damaging eggs and embryos of sparrows.

The most probable cause of the decline in overall population in birds owing to mobile and cell phone base stations is the effect on reproductive success in birds. ${ }^{3}$ The electromagnetic field adversely impacts the reproductive success of kestrels (Falco sparverius). The hatching success is reduced in the birds though the fertility and fledging success is increased. ${ }^{12}$ The current scientific evidence indicates that prolonged exposure to electromagnetic fields at the levels encountered in the environment, may affect the immune system function. Pulsed magnetic fields can influence the development and incidence of abnormalities in chicken embryos ${ }^{13}$ while a stressed immune system may increase the susceptibility of a bird to infectious diseases. Plumage deterioration is the first sign of stress and illness in the birds. It has been found that the plumage of the birds exposed to microwaves get discolored though each species and each individual may show different susceptibility to radiation, because vulnerability depends upon genetic tendency, physiologic and neurological state of the irradiated organism. ${ }^{14-16}$

In nutshell, it appears increased exposure to electromagnetic field and radiations in the surrounding air support a decline in the population of various species in the country though the impact of other factors like urbanization, climate change, global warming, habitat loss and environmental pollutants cannot be completely neglected.

\section{Conclusion}

Cellular phones are essential to our lives for all the communications. However, their extensive usage and upgraded services continue to threaten the species diversity and the lives of different birds in the region. While the cellular phones cannot be completely wiped out of our lives, it is important to find an alternative technology that can keep the wireless communication strong but do not pose any risk to the lives of these little creatures around us. Bird diversity is important to keep the plant diversity and all the researchers must try to begin looking for alternative technology for safe surroundings.

\section{Acknowledgments}

None.

\section{Conflicts of interest}

The authors declare there are no conflicts of interest. 


\section{Funding}

None.

\section{References}

1. Balmori A, Hallberg O. The urban decline of the House Sparrow (Passer domesticus): a possible link with electromagnetic radiation. Electromagn Biol Med. 2007;26(2):141-151.

2. Kumar G. Cell Tower Radiation. Electrical Engineering Department. IIT Bombay. 2010.

3. Fernie KJ, Reynolds SJ. The effects of electromagnetic fields from power lines on avian reproductive biology and physiology: a review. $J$ Toxicol Environ Health B Crit Rev. 2005;8(2):127-140.

4. Panagopoulos DJ, Margaritis LH. Mobile telephony radiation effects on living organisms. In: Harper AC, Buress RV, editors. Mobile telephones, networks, applications and performance. New York: Nova Science Publishers; 2008:107-149.

5. Everaert J, Bauwens D. A possible effect of electromagnetic radiation from mobile phone base stations on the number of breeding House Sparrows (Passer domesticus). Electromagn Biol Med. 2007;26(1):6372.

6. Summers Smith, Denis J. Changes in the House Sparrow Population in Britain. International Studies on Sparrows. 2003:23-37.
7. Balmori A. Possible effects of electromagnetic fields from phone masts on a population of White Stork (Ciconiaciconia). Electromagnetic Biology and Medicine. 2005;24(2):109-119.

8. Bharucha E. The Biodiversity of India. Mapin Publishing Pvt Ltd. 2002.

9. Dongre S. Verma R. Effect of Cell Phone Radiation on Gauriya Sparrows Passer domesticus. International Research Journal. 2009:2(7):51-52.

10. Durgam DK, Shweta S, Singh RK. Effect of mobile tower radiation on birds in Bijapur district, Chhattisgarh. World Journal of Pharmacy and Pharmaceutical Sciences. 2017;6(9):1221-1229.

11. Manish K, Singh RK. Effect of Mobile Tower radiation on birds in rural and urban areas of Drug district. WJPPS. 2018;7(6).

12. Balmori A. Electromagnetic pollution from phone masts. Effects on wildlife. Pathophysiology. 2009;16(2):191-199.

13. Batellier F, Couty I, Picard D, et al. Effects of exposing chicken eggs to a cell phone in "call" position over the entire incubation period. Theriogenology. 2008;69(6):737-745

14. Hyland GJ. Physics and Biology of Mobile Telephony. Lancet. 2000;356(9244):1833-1836.

15. Clark MP. Networks and Telecommunications. 2nd ed. Wiley. 2001.

16. De Laet J, Summers-Smith JD. The status of the urban house sparrow Passer domesticus in north-western Europe: a review. J Ornithol. 2007;148(Suppl 2):S275-S278. 